\title{
Incidence of unilateral and bilateral benign paroxysmal positional vertigo when the left and right Dix-Hallpike manoeuvres are positive: a model based on the sense of torsional nystagmus
}

\author{
Incidenza della vertigine parossistica benigna bilaterale e monolaterale \\ in caso di positività alla manovra Dix-Hallpike a destra e sinistra: \\ modello basato sul verso del nistagmo rotatorio
}

\author{
Esther Domènech-Vadillo1, María Guadalupe Álvarez-Morujo De Sande², Rocío González-Aguado², \\ Gloria Guerra-Jiménez4, Hugo Galera-Ruiz ${ }^{5}$, Antonio Ramos-Macías ${ }^{4}$, Carmelo Morales-Angulo³, \\ Antonio José Martín-Mateos², Enric Figuerola-Massana1, Emilio Domínguez-Durán ${ }^{5}$ \\ ${ }^{1}$ Hospital Universitari Joan XXIII, Tarragona, Spain; ${ }^{2}$ Hospital Universitario Puerta del Mar, Cádiz, Spain; ${ }^{3}$ Hospital Universitario \\ Marqués de Valdecilla, Santander, Spain; ${ }^{4}$ Complejo Hospitalario Universitario Insular Materno-Infantil, Las Palmas de Gran Canaria, \\ Spain; ${ }^{5}$ Hospital Infanta Luisa, Sevilla, Spain
}

\section{SUMMARY}

Patients presenting with nystagmus indicative of benign paroxysmal positional vertigo (BPPV) during the left and the right Dix-Hallpike manoeuvres (DHMs) are frequently seen in clinical practice. In such cases, BPPV may be unilateral or bilateral. The aim of this study is to describe the incidence of unilateral and bilateral BPPV when both DHMs are positive, taking into account the sense of the torsional component of nystagmus. This is a prospective multicentre study. BPPV patients were classified into three groups: patients with only one positive DHM (control group, CG), patients showing positive bilateral DHM with nystagmus in the same sense in both DHMs (same sense group, SSG) and patients showing positive bilateral DHM with the torsional component of nystagmus beating in opposite senses in each DHM (opposite sense group, OSG). Only one Epley Manoeuvre (EM) was performed on all patients. Based on the ipsilateral result of the EM, the contralateral result of the same EM and the BPPV resolution rate in the control group, a model was developed to predict the incidence of unilateral and bilateral BPPV in the SSG and the OSG. There were 234 patients in the control group, 20 in the SSG and 23 in the OSG. The model estimated that the percentage of unilateral BPPV would be $89.5 \%$ in SSG and $38.7 \%$ in OSG. Using these findings, we conclude that when both DHMs are positive, BPPV may be unilateral or bilateral. If the torsional components of both nystagmuses beat in the same sense, it is more likely to be unilateral BPPV. If the torsional components beat in opposite senses, both situations can be considered equally likely.

KEY WORDS: benign paroxysmal positional vertigo, multi-canal BPPV

\section{RIASSUNTO}

Frequentemente nella pratica clinica si valutano pazienti che mostrano alle manovre di Dix-Hallpike (DHM), verso destra e verso sinistra, il nistagmo tipico della vertigine posizionale parossistica benigna (BPPV). In questi casi la BPPV può essere unilaterale o bilaterale. Lo scopo del presente studio è quello di descrivere l'incidenza della BPPV unilaterale e bilaterale, quando entrambe le DHM sono positive, considerando il verso della componente torsionale del nistagmo. In questo studio prospettico multicentrico i pazienti sono stati suddivisi in tre gruppi: pazienti con solo una DHM positiva (gruppo di controllo, $C G)$, pazienti con DHM positiva bilateralmente e con nistagmo battente nello stesso verso evocabile in entrambe le manovre (gruppo stesso verso, SSG), pazienti con DHM positiva bilateralmente e con nistagmo avente componente torsionale con verso opposto nelle due manovre (gruppo verso opposto, OSG). La manovra di Epley (EM) è stata condotta su tutti
Received: June 1, 2018

Accepted: December 19, 2018

Published on line: September 30, 2019

Correspondence

E. Domínguez-Durán

Hospital Infanta Luisa. Calle San Jacinto 87, 41010

Sevilla, Spain

Tel. +34610875489

E-mail: emiliodominguezorl@gmail.com

Funding

None.

Conflict of interest

The Authors declare no conflict of interest.

How to cite this article: Domènech-Vadillo $\mathrm{E}$, Álvarez-Morujo De Sande MG, GonzálezAguado R, et al. Incidence of unilateral and bilateral benign paroxysmal positional vertigo when the left and right Dix-Hallpike manoeuvres are positive: a model based on the sense of torsional nystagmus. Acta Otorhinolaryngol Ital 2020;40:144-151. https://doi. org/10.14639/0392-100X-2214

(c) Società Italiana di Otorinolaringoiatria e Chirurgia Cervico-Facciale

\section{(c) (1) $)$}

This is an open access article distributed in accordance with the CC-BY-NC-ND (Creative Commons Attribution-NonCommercial-NoDerivatives 4.0 International) license. The article can be used by giving appropriate credit and mentioning the license, but only for non-commercial purposes and only in the original version. For further information: https:// creativecommons.org/licenses/by-nc-nd/4.0/deed.en 
i pazienti. Considerando i risultati ottenuti dalla EM e il tasso di risoluzione della BPPV nel CG, è stato sviluppato un modello predittivo dell'incidenza della BPPV unilaterale e bilaterale negli SSG e OSG. Il CG comprendeva 234 pazienti, 20 erano inclusi invece nel SSG e 23 nell'OSG. Il modello ha stimato che la percentuale di BPPV unilaterale ammonterebbe a 89,5\% nel SSG e 38,7\% nel OSG. In conclusione, se entrambe le DHM sono positive, la BPPV può essere sia unilaterale che bilaterale. Se la componente torsionale dei nistagmi batte nello stesso verso, è più probabile che la BPPV sia unilaterale; se invece tale componente ha verso opposto alle DHM, le due condizioni possono considerarsi ugualmente probabili.

PAROLE CHIAVE: vertigine posizionale parossistica benigna, BPPV multi-canale

\section{Introduction}

Benign paroxysmal positional vertigo (BPPV) is the most frequent cause of vertigo ${ }^{1}$. The most widely accepted theory states that BPPV is caused by otoconia which become detached from the otoconial macula and reside in the semicircular canals. When changes in head position occur in the plane of these semicircular canals, gravity causes these otoconia to move, which impairs endolymph flow, thus activating the ciliary cells in ampullary receptors, a mechanism known as canalithiasis ${ }^{2}$. Another less frequent cause of BPPV is cupulolithiasis ${ }^{3}$, which occurs when otoconia become attached to the cupula of a semicircular canal, thus changing the canal's sensitivity to gravity.

The Dix-Hallpike manoeuvre (DHM) ${ }^{4}$ causes the otoconia in the posterior semicircular canals (PSC) to move. Canalithiasic BPPV of the PSC is diagnosed when a combination of torsional nystagmus and upbeating vertical nystagmus is observed ${ }^{5}$. It is currently accepted that BPPV may involve more than one canal, which is known as lithiasis of multiple canals (mc-BPPV) ${ }^{5}$.

In clinical practice, patients presenting torsional nystagmus with a vertical component in both DHMs - left and right - are not infrequent ${ }^{6}$. Such a finding may correspond to different physiopathological situations, as the DHM is not specific to a certain PSC and may indirectly stimulate the contralateral one to a lesser degree.

Thus, when both DHMs are positive, the BPPV may be unilateral, with the DHM contralateral to the affected ear causing the otoconia to move and producing ampullopetal deflection of the cupula. This would mimic bilateral BPPV, thus producing pseudo-bilateral benign paroxysmal positional nystagmus (pb-BPPN) ${ }^{7}$. However, the BPPV may also be bilateral and produce hard-to-interpret nystagmuses due to the simultaneous stimulation of several canals ${ }^{8}$.

To facilitate clinical assessment, we need to find a way to differentiate between unilateral and bilateral BPPV of the PSC using the nystagmuses observed in both DHMs and to estimate the probability that these nystagmuses are caused by unilateral or bilateral BPPV.

The aim of this study is to describe the incidence of unilateral and bilateral BPPV when both the left and right DHMs are positive by using the sense of the torsional component of the observed nystagmuses.

\section{Materials and methods}

This was a multicentric, prospective, descriptive study. The research protocol was approved by the Ethics Committee of the main participating hospital. Between April $1^{\text {st }} 2015$ and March $31^{\text {st }} 2016$ all patients presenting to the Otoneurology Unit of any of the five participating hospitals with suspected BPPV were prospectively recruited. Patients undergoing the Epley manoeuvre (EM) were required to sign an informed consent form before being included in the study.

All patients underwent anamnesis for possible risk factors that could potentially impair the success of the Epley manoeuvre ${ }^{9}$ and were also given complete otoneurological examination including bilateral head impulse tests ${ }^{10}$, determination of presence of nystagmus in all positions of gaze and Pagnini-McClure manoeuvres. Patients were also subjected to left and right DHMs. Subsequently, they were split into two groups: those presenting typical nystagmus in only one DHM (control group) (CG) and those presenting typical nystagmus both in the left and the right DHM. We used the term "typical nystagmus" to describe a torsional positional nystagmus, with a duration of under 60 seconds, elicited by the DHM on one or both sides, with a latency of one to a few seconds. The presence or absence of nystagmus was evaluated with the naked eye.

Patients in the CG underwent the corresponding EM. Patients who had presented nystagmus in both DHMs were then classified into two groups: those presenting torsional nystagmus in the same sense in both the left and right DHMs (same sense group, SSG) or those presenting clockwise torsional nystagmus in the left DHM and counterclockwise torsional nystagmus in the right DHM (opposite sense group) (OSG). SSG patients presenting clockwise torsional nystagmuses on both sides underwent left EM; those presenting counter-clockwise nystagmuses on both sides underwent right EM. Patients in the OSG underwent the EM to the side where the higher-intensity nystagmus had been observed. If both nystagmuses were of similar intensity, the side where the patient reported having stronger symptoms was chosen. After the EM, the physician advised patients to sleep with the head of bed elevated at $30^{\circ}$ that night. Patients were given an appointment for a follow-up visit 
7 days later. Patients were judged to have recovered from ipsilateral BPPV if nystagmus was absent in the follow-up DHM even if they presented vertigo in that position.

Patients presenting any of the following characteristics were excluded from the study: spontaneous nystagmus different from physiologic gaze-evoked nystagmus, involvement of the horizontal canal detected in the left or right PagniniMcClure manoeuvre ${ }^{11,12}$, absence of nystagmus observed without Frenzel glasses in both DHMs, atypical nystagmus, which is not a combination of torsional and upbeating vertical nystagmus in at least one of the DHMs, nystagmus lasting for 60 seconds or longer, patients refusing to undergo EM, patients failing to attend the follow-up visit and patients where the occurrence of nystagmus could not be verified during the follow-up visit as they closed their eyes during the DHM. Figure 1 outlines the selection process.

Using the results, a model was designed to predict the incidence of unilateral and bilateral BPPV in the SSG and OSG using three pieces of data: the ipsilateral outcome of the EM, the contralateral outcome of the same EM and the BPPV resolution rate in the CG.

Figure 1 shows the steps involved in the construction of the model. According to the model, the assumed diagnosis was unilateral BPPV in patients who show negative nystagmus in both DHMs after only one EM. The assumed diagnosis was bilateral BPPV in patients who show negative nystagmus in the DHM ipsilateral to the EM, but not in the contralateral one. In patients where the ipsilateral DHM did not become negative, it was not possible to tell whether BPPV is unilateral or bilateral; however, the number of subjects with unilateral BPPV in this group can be estimated by applying the BPPV resolution rate in the control group to patients with assumed unilateral BPPV.

The model allowed us to calculate the proportions of unilateral and bilateral BPPV in the SSG and OSG and the confidence intervals for this data were also calculated.

\section{Results}

During the study, 234 patients were included in the CG, 20 were included in the SSG and 23 were included in the OSG. Median age was 63 years; $71.5 \%$ were women. BPPV affected the right ear in $48.9 \%$ of CG patients; in the SSG and the OSG -presumably with bilateral BPPV - the right ear was the treated ear in 60 and $56.5 \%$ of cases, respectively. No significant between-group differences were found in median age $(p=0.258)$, age distribution $(p=0.178)$, gender proportion $(\mathrm{p}=0.133)$ or side of the treated ear $(\mathrm{p}=0.526)$.

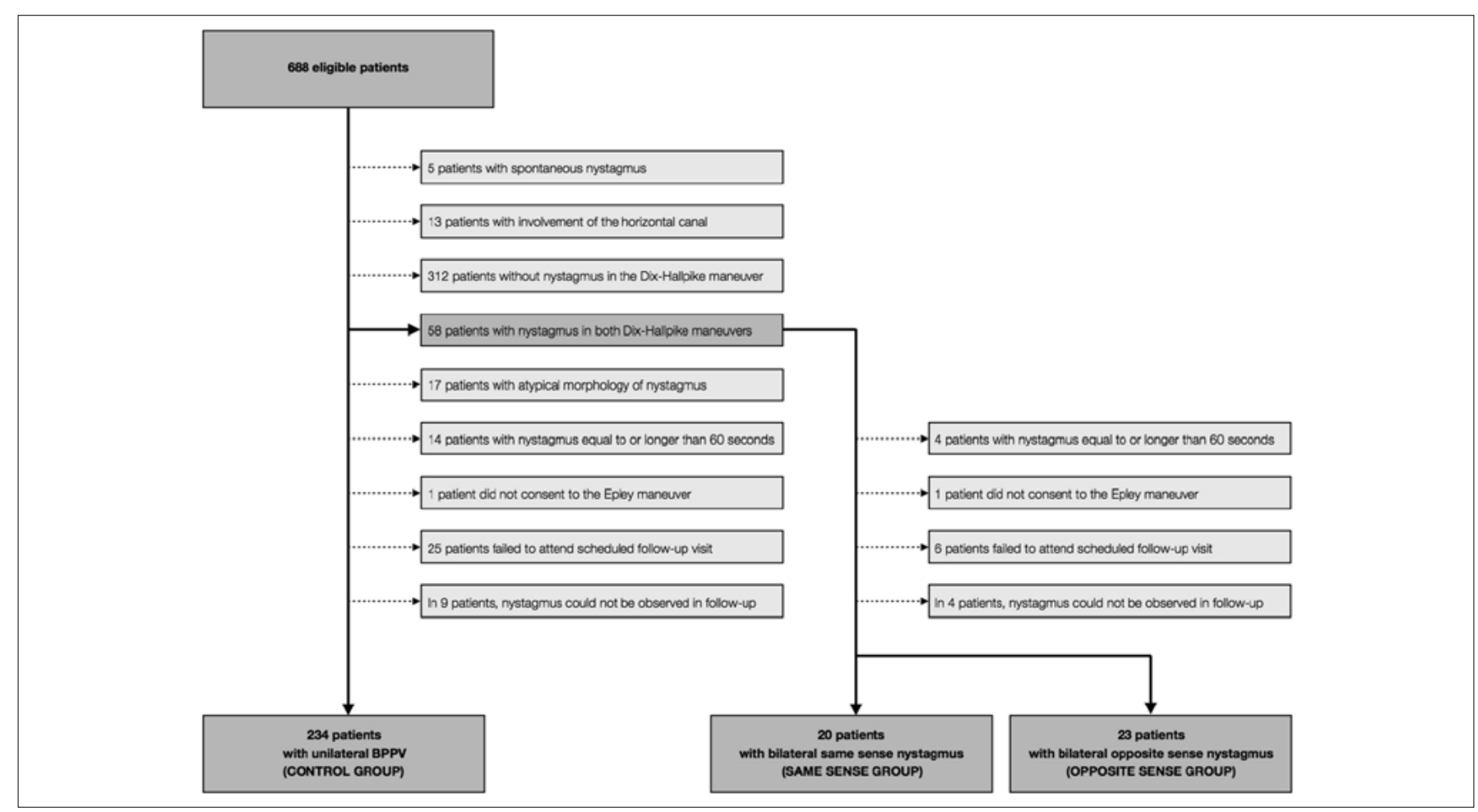

Figure 1. Selection of patients to form the three groups in the study: patients with unilateral BPPV (control group), patients showing nystagmus in both DHMs with the torsional component beating in the same sense (same sense group) and patients showing nystagmus in both DHMs with the torsional component beating clockwise in the left DHM and counter-clockwise in the right DHM (opposite sense group). 
One week after the EM, 157 patients in the CG showed negative nystagmus in the DHM on the treated ear, thus giving a resolution rate of $67.1 \%$; 12 SSG patients showed negative DHMs on both sides and 2 SSG patients only a negative DHM on the treated ear (70\% ipsilateral negativisation); 6 OSG patients showed negative DHMs on both sides and 6 OSG patients showed negative DHM only on the treated ear side (52.2\% ipsilateral negativisation). No significant between-group differences were found in the percentage of ipsilateral negativisation $(\mathrm{p}=0.328)$. Table I summarises the results observed.

Figure 2 shows the steps taken to create a model to estimate the incidence of unilateral and bilateral BPPV. In the third step, the rate of negativisation of nystagmus in the $\mathrm{CG}$ was used to calculate the number of patients with unilateral BPPV in the SSG and the OSG. According to the model, the proportion of unilateral BPPV in the SSG was 89.5\% (95\% CI 66.3-98.0\%), while in the OSG it was $38.7 \%$ (95\% CI 20.1-60.8\%).

Using the model, patients were reallocated into three new groups: unilateral BPPV (252 patients; $91.0 \%$ of total), bilateral BPPV (8 patients; $2.9 \%$ of total) and undifferentiated patients, where the EM failed to make the ipsilateral DHM negative (17 patients; $6.1 \%$ of total).

Subsequently, the unilateral and bilateral groups were compared to examine two factors which have been associated with a higher risk of bilateral BPPV in the medical literature: a background of traumatic brain injury (TBI) before the start of symptoms and history of previous BPPV in any ear. Looking at the TBI background showed that no bilateral BPPV patient reported having suffered TBI in the three months before the start of symptoms, whereas $7.5 \%$ of unilateral BPPV patients did, although the difference was not statistically significant $(\mathrm{p}=0.420)$. As for previous BPPV in any ear, $12.8 \%$ of unilateral and $50 \%$ of bilateral BPPV patients reported a history of BPPV and this difference reached statistical significance $(\mathrm{p}=0.015)$.

\section{Discussion}

The main contribution of this study to the scientific literature is the demonstration that BPPV may be unilateral or bilateral regardless of the sense of the torsional component of DHMelicited nystagmuses. When torsional components beat in the same sense, unilateral BPPV was the most likely diagnosis (89.5\% of cases): left in the case of clockwise nystagmus and right in the case of counterclockwise nystagmus. However, although less likely, bilateral BPPV was also possible.

When torsional components beat in opposite senses - clockwise in the left DHM and counter-clockwise in the right DHM - there were more cases of bilateral BPPV cases in our sample $(61.3 \%)$, although interval-based estimations did not support the claim that bilateral BPPV was more frequent than unilateral BPPV. Therefore, in this case, both types of BPPV were possible and their incidence may be the same.

Figure 3 shows that both unilateral and bilateral BPPV may cause nystagmus in both DHMs with the torsional components in opposite senses.

Pseudo-bilateral and pseudo-unilateral benign paroxysmal positional nystagmus

As hypothesised throughout herein and as demonstrated by the data from our population, nystagmuses observed in DHMs may correspond to different physiopathological situations.

At present, the only diagnostic tool available to estimate the situation of otoconia residing in a semicircular canal is the observation of nystagmus after a diagnostic positional manoeuvre such as the DHM. Thus, we found cases of pbBPPN (pseudo-bilateral BPPN), which suggest bilateral BPPV whereas the condition is actually unilateral, as well as cases (as found in our study) of patients with pseudounilateral benign paroxysmal positional nystagmus (puBPPN), which suggest unilateral BPPV whereas the condition is actually bilateral.

$\mathrm{Pu}-\mathrm{BPPN}$ has not been described in the scientific literature. It consists of bilateral positional nystagmus, compatible with canalolithiasis of only one PSC, although there is bilateral PSC BPPV. In our population, we verified only two cases of patients with pu-BPPN $(0.72 \%$ of the population with BPPV of the PSC). However, given that in some patients it was not possible to determine whether the BPPV was unilateral or bilateral, this percentage might be higher, representing about $10.5 \%$ of the SSG (95\% CI 1.9-33.7\%). Due to the existence of pb-BPPN and pu-BPPN, it is especially important to construct a model, such as the one we offer here, for clinicians to be aware of the different possible diagnoses in clinical BPPV cases where positional manoeuvres do not offer a specific diagnosis.

Table I. Results of the EM in the three groups in the study.

\begin{tabular}{lcccc} 
& Bilateral resolution & Ipsilateral resolution only & Without ipsilateral resolution & N \\
CG & - & $157(67.1 \%)$ & $77(32.9 \%)$ & 234 \\
SSG & $12(60 \%)$ & $2(10 \%)$ & $6(30 \%)$ & 20 \\
OSG & $6(26.1 \%)$ & $6(26.1 \%)$ & $11(47.8 \%)$ & 23 \\
\hline
\end{tabular}




\section{Comparison of populations}

If one compares the percentage of bilateral BPPV in our population $(5.8 \%)$ with that found in other publications (ranging between 8 and $10.9 \%)^{8,13,14}$, our percentage seemed to be lower, although the differences were not statistically significant. This finding may be accounted for by the fact that our model can detect pb-BPPN cases, which are no longer considered as bilateral cases.

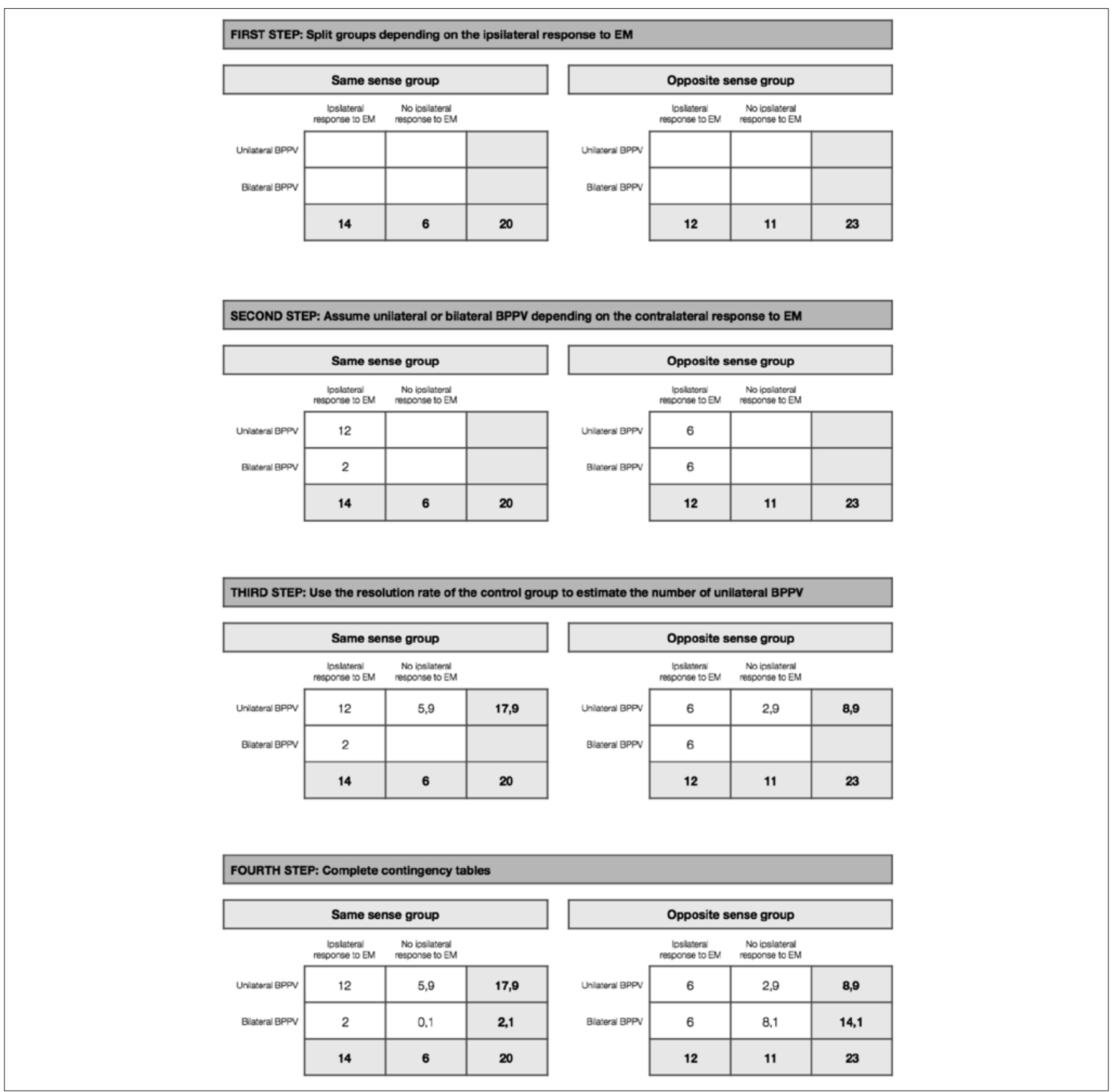

Figure 2. Steps taken to create a model to estimate the incidence of unilateral and bilateral BPPV. First step: creation of a contingency table for the SSG and another for the OSG. These tables show the ipsilateral response to the EM and the number of patients with unilateral or bilateral BPPV. Patients were classified according to their ipsilateral response to the EM. Second step: patients responding to the EM were classified as having unilateral BPPV or bilateral BPPV depending on whether the EM was successful in neutralising the nystagmus in the contralateral DHM. Note that in patients where the EM failed to neutralise ipsilateral nystagmus (second column), the contralateral response cannot be used to differentiate between unilateral and bilateral BPPV. Third step: the EM resolution rate in the control group (67.1\%) was used to calculate the total number of patients with unilateral BPPV. Fourth step: contingency tables were completed. 


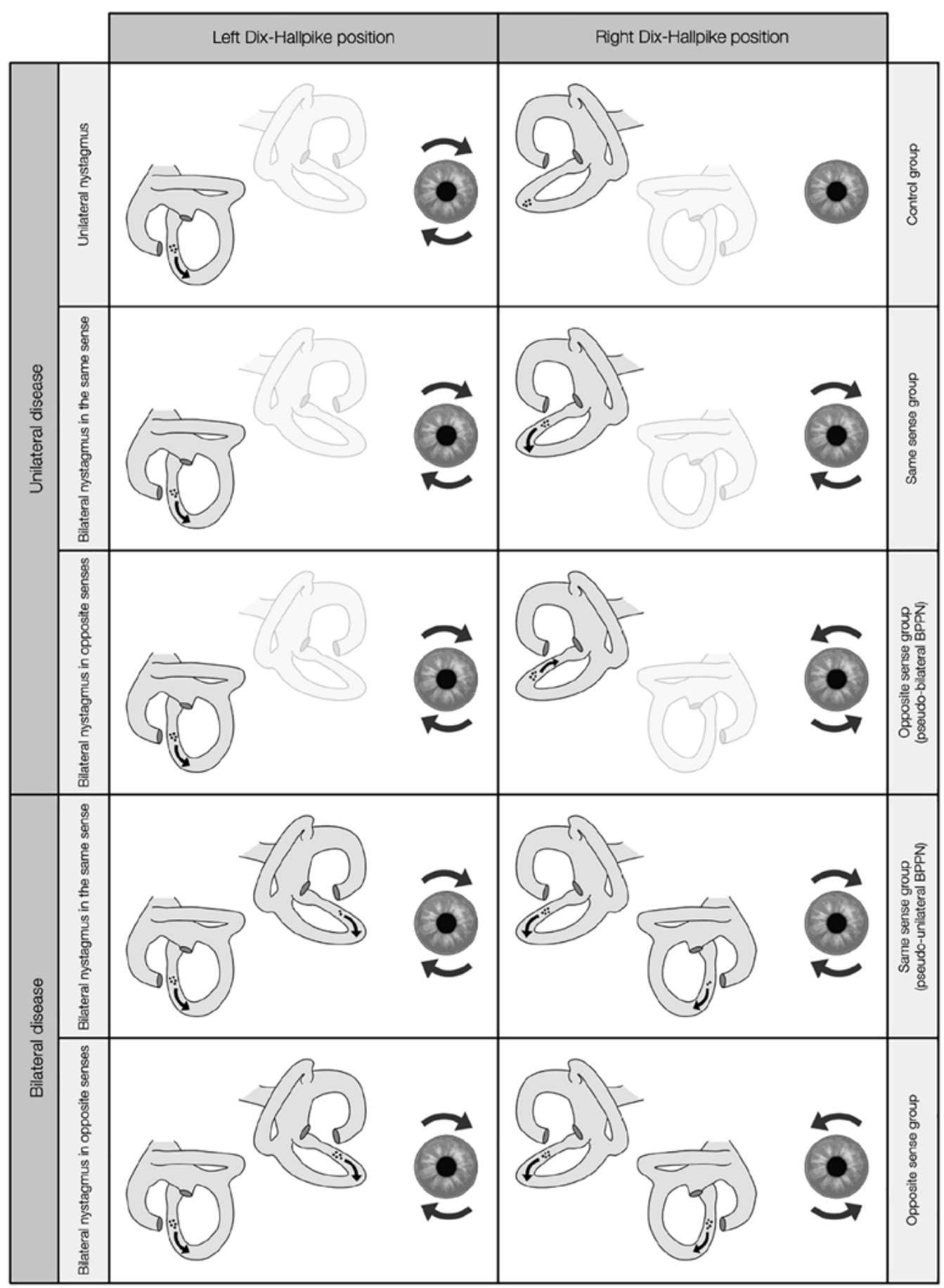

Figure 3. Explanation of how both unilateral and bilateral BPPV can produce clockwise and counter-clockwise nystagmus in the DHMs. The view of the inner ears is from the perspective of an examiner sitting behind the patient's head. The horizontal semi-circular ducts were dissected to offer an enhanced view of the PSC and their ampullae. In case of unilateral BPPV (represented as left BPPV in the figure) on the left DHM, the otoconia move ampullofugally, thus generating clockwise nystagmus. In the right DHM, either the otoconia do not move, thus not generating nystagmus, or they may move ampullofugally, thus generating clockwise nystagmus, or they may move ampullopetally, thus generating counterclockwise nystagmus (pseudo-bilateral BPPN). In the case of bilateral BPPV (higher involvement of the left ear represented in the figure) in the left DHM, the otoconia of the left ear move ampullofugally, generating clockwise nystagmus. In the right $\mathrm{DHM}$, the otoconia of the right ear move ampullofugally, generating counterclockwise nystagmus. The counter-clockwise nystagmus might not inhibit the clockwise nystagmus generated by the left ear as fewer otoconia are involved (pseudo-unilateral BPPN), but it might do so as the right otoconia migrate at a faster rate than the left otoconia and that would create a more intense nystagmus (from Squires, $2004{ }^{21}$, mod.). 
A comparison of the different groups of patients in our population, which were classified according to the DHM outcome or the unilateral/bilateral BPPV type, revealed no significant differences in the proportion of men and women, median age, or age distribution. In a study by Soto-Varela et al. ${ }^{8}$, no differences were found in the proportion of men and women, but differences were reported in age distribution. Although some studies ${ }^{13-15}$ report that a TBI background is more common in patients with bilateral BPPV than in those with unilateral BPPV, in our sample (as in the Soto-Varela study) no significant differences were found. Additionally, as in their study, we found significant differences in the percentage of patients with a history of BPPV, which was more frequent in those with bilateral $\mathrm{BPPV}^{8}$.

\section{Limitations of the model}

Although built on physiopathological bases, this model attempted to explain an unknown underlying reality; therefore, it is subject to certain assumptions that are detailed below:

1. Only the torsional component of nystagmus was used in the model, while the vertical component was disregarded. The rationale behind this was the fact that the torsional component in BPPV of the PSC is more prominent than the vertical one ${ }^{16}$, thus making it easier for clinicians to identify without Frenzel glasses. Other models have been proposed, such as that of Zhao el al., which uses the vertical component and yields mcBPPV diagnosis for upbeating vertical components on both DHMs and unilateral BPPV for an upbeating component in one DHM and a downbeating component in the other ${ }^{17}$ or that of Pollak et al., which uses the disappearance of the torsional component of nystagmus during the head down test to identify true bilateral BPPV ${ }^{18}$. Another method to differentiate between unilateral and bilateral BPPV has been proposed by Imai et al. ${ }^{6}$, where an infrared charge-coupled device camera is used to detect the rotation vector of nystagmus in three dimensions and is used as a means of differentiating between the two types. Although this method can differentiate between unilateral and bilateral BPPV when nystagmuses in each DHM beat in opposite senses, it requires instrumental examination and a complex analysis of results.

2. When nystagmuses in both DHM beat in opposite senses, the side which shows the most intense nystagmus following the manoeuvre is always the most affected one. In this model, it is assumed that the ear with the most intense nystagmus is always the most affected one and that it has a larger otoconia load than the contralateral ear. The combination of Figure 3 and the third law of Ewald ${ }^{19}$, which postulates that, in the PSC, the flow from the cupula to the duct generates a nystagmus of higher intensity than the flow in the opposite sense, makes this seem like a reasonable assumption. However, the complexity of the resulting nystagmus in the case of multicanal BPPV, raises the question whether unusual locations of the otoconia within the semicircular canals could be possible, thus invalidating this assumption.

3. The percentage of BPPV cases involving the superior semi-circular canal is so low that it can be disregarded. In our population, only $2 \%$ of cases, where only one canal was involved, correspond to the superior semicircular canal (95\% CI $0.8-4.4 \%)$. If such a confidence interval were extrapolated to mc-BPPV cases, the superior canal would be involved in only 0 to $2 \%$ of our patients with nystagmus in both DHMs, a proportion low enough that it should not affect the results of the model in a significant way.

4. Clockwise nystagmuses in both DHMs cannot correspond to unilateral right BPPV and counter-clockwise nystagmuses in both DHMs cannot correspond to unilateral left BPPV. In theory, unilateral BPPV with otoconia near the crus commune could cause such situations due to ampullopetal flow in both DHMs. However, such a situation seems unlikely due to the fact that otoconia in that location should spontaneously descend to the utricle.

5. The EM cannot resolve BPPV of the contralateral ear. For this model to be valid, one must assume that the EM in one ear cannot relocate displaced otoconia in the contralateral ear. Although, as indicated in Figure 3, both DHMs may cause ampullofugal displacement of the otoconia in either ear, the EM produces a spin that would favour contralateral ampullopetal displacement of the otoconia in the PSC and thus it cannot resolve contralateral BPPV.

6. The BPPV resolution rate of the EM in one ear is not influenced by DHM findings in the contralateral ear or the occurrence of bilateral BPPV. No significant differences were found between the CG, SSG and OSG, regarding the percentage of ipsilateral negativisation of the DHM after the EM. However, an earlier study identified risk factors that may affect the EM outcome in bilateral BPPV in the same population ${ }^{20}$. In this study, the risk factors shown to affect the EM outcome were compared by looking at the three groups. No significant betweengroups differences were found regarding the percentage of subjects with a history of previous BPPV. However, significant differences were found in the subjective intensity of nystagmus, which was higher in the OSG than in the CG. Such a finding could be accounted for by a 
larger number of otoconia floating bilaterally and we argue that this could not affect the model in a significant way.

7. In the 7 days between EM and the follow-up visit, there is no spontaneous recovery of the contralateral ear. When we were designing this study, we decided that the follow-up visit should be as soon as possible after the initial visit in order to prevent any possible bias resulting from such a situation. In our population, the median time lapse between the beginning of symptoms and the application of the EM was 45 days; therefore, spontaneous recovery in 7 days seemed unlikely.

8. In the 7 days between the EM and follow-up examination, contralateral BPPV does not develop. The annual BPPV incidence was calculated to be $0.6 \%^{1}$; the weekly incidence must be even lower and therefore this risk was disregarded in this model.

In summary, despite all these objections, the assumptions of the model seem to be reasonable and any possible biases seem to be negligible; therefore, we postulate that this model can reasonably account for the reality of endolymph alterations when both DHMs are positive.

\section{Conclusions}

When both left and right DHMs are positive and show torsional nystagmus, both unilateral and bilateral BPPV are possible. When the torsional nystagmus components in both DHMs beat in the same sense, unilateral BPPV is more likely although bilateral BPPV is also possible. When the torsional components beat in opposite senses, unilateral and bilateral BPPV are equally likely.

\section{References}

9 von Brevern M, Radtke A, Lezius F, et al. Epidemiology of benign paroxysmal positional vertigo: a population based study. J Neurol Neurosurg Psychiatry 2007;78:710-5. https://doi.org/10.1136/jnnp.2006.100420

10 Hall SF, Ruby RR, McClure JA. The mechanics of benign paroxysmal vertigo. J Otolaryngol 1979;8:151-8.

11 Schuknecht HF. Cupulolithiasis. Arch Otolaryngol Chic Ill 1960. 1969;90:765-78. https://doi.org/10.1001/archotol.1969.00770030767020

12 Dix MR, Hallpike CS. The pathology, symptomatology and diagnosis of certain common disorders of the vestibular sys- tem. Ann Otol Rhinol Laryngol 1952;61:987-1016. https://doi. org/10.1177/000348945206100403

13 von Brevern M, Bertholon P, Brandt T, et al. Benign paroxysmal positional vertigo: diagnostic criteria. J Vestib Res Equilib Orientat 2015;25:105-17. https://doi.org/10.3233/VES-150553

14 Imai T, Takeda N, Sato G, et al. Differential diagnosis of true and pseudo-bilateral benign positional nystagmus. Acta Otolaryngol (Stockh) 2008;128:151-8. https://doi.org/10.1080/00016480701477594

15 Steddin S, Brandt T. Unilateral mimicking bilateral benign paroxysmal positioning vertigo. Arch Otolaryngol Head Neck Surg 1994;120:133941. https://doi.org/10.1001/archotol.1994.01880360037007

16 Soto-Varela A, Rossi-Izquierdo M, Santos-Pérez S. Benign paroxysmal positional vertigo simultaneously affecting several canals: a 46-patient series. Eur Arch Otorhinolaryngol 2013;270:817-22. https://doi.org/10.1007/s00405-012-2043-2

17 Epley JM. The canalith repositioning procedure: for treatment of benign paroxysmal positional vertigo. Otolaryngol Head Neck Surg 1992;107:399-404. https://doi.org/10.1177/019459989210700310

18 Halmagyi GM, Curthoys IS. A clinical sign of canal paresis. Arch Neurol 1988;45:737-9. https://doi.org/10.1001/archneur.1988.00520310043015

19 Pagnini P, Nuti D, Vannucchi P. Benign paroxysmal vertigo of the horizontal canal. ORL J Otorhinolaryngol Relat Spec 1989;51:16170. https://doi.org/10.1159/000276052

20 McClure JA. Horizontal canal BPV. J Otolaryngol 1985;14:30-5.

21 Tomaz A, Ganança MM, Ganança CF, et al. Benign paroxysmal positional vertigo: concomitant involvement of different semicircular canals. Ann Otol Rhinol Laryngol 2009;118:113-7. https://doi. org/10.1177/000348940911800206

22 Balatsouras DG. Benign paroxysmal positional vertigo with multiple canal involvement. Am J Otolaryngol 2012;33:250-8. https://doi. org/10.1016/j.amjoto.2011.07.007

23 Suarez H, Alonso R, Arocena M, et al. Clinical characteristics of positional vertigo after mild head trauma. Acta Otolaryngol (Stockh) 2011;131:377-81. https://doi.org/10.3109/00016489.2010.534113

24 Bronstein A, Lempert T. Positional vertigo. In: Dizziness: a practical approach to diagnosis and management. $1^{\text {st }}$ ed. Cambridge: Cambridge University Press 2007.

25 Zhao F, Zhuang J, Xie X, et al. Management of bilateral benign paroxysmal positional vertigo with Dix-Hallpike test. Zhonghua Nei Ke Za Zhi 2014;53:764-7.

26 Pollak L, Stryjer R, Kushnir M, et al. Approach to bilateral benign paroxysmal positioning vertigo. Am J Otolaryngol 2006;27:91-5. https://doi.org/10.1016/j.amjoto.2005.07.012

27 Ewald JR. Physiologische Untersuchungen ueber das Endorgan des Nervus Octavus. Wiesbaden: J.F. Bergmann 1892.

28 Domínguez-Durán E, Domènech-Vadillo E, Álvarez-Morujo de Sande MG, et al. Analysis of risk factors influencing the outcome of the Epley maneuver. Eur Arch Otorhinolaryngol 2017;274:3567-76. https://doi.org/10.1007/s00405-017-4674-9

29 Squires TM, Weidman MS, Hain TC, et al. A mathematical model for top-shelf vertigo. J Biomech 2004;37:1137-46. https://doi. org/10.1016/j.jbiomech.2003.12.014 